Bangladesh J. Genet Pl. Breed: 20(2): 43-50, 2007

\title{
PRODUCTION OF HAPLOIDS AND POLYEMBRYOS IN WHEAT (Triticum aestivum L.) THROUGH WHEAT $\times$ MAIZE SYSTEM
}

\author{
U. Asad ${ }^{1}$, A. K. M. Shamsuddin, S. Alam and M. M. Rahman ${ }^{2}$ \\ Department of Genetics and Plant Breeding \\ Bangladesh Agricultural University \\ Mymensingh 2202, Bangladesh
}

\begin{abstract}
Six varieties of spring wheat such as Mayoor, Sebia, Prodip, Bulbul, Bijoy, Sowgat were crossed with a single maize variety Pop corn as pollinator. Fertilization of wheat eggs, formation, retention and development of haploid embryos were facilitated by the application of 2, 4-D at 100ppm. The haploid embryos were cultured on MS medium, which regenerated haploid plants. Highly significant variations were observed for the characters related to haploid production such as development of caryopsis, recovery of embryos and regeneration of haploid plants over total pollinated florets. The highest caryopsis setting over pollinated florets was noticed in the variety Sebia. Recovery of embryos over caryopsis was the highest in the variety Bijoy. Germination of embryos over total embryos and regeneration of haploid plants over total pollinated florets were highest in the variety Mayoor. At the time of embryo rescue, occurrence of more than one embryo in a single caryopsis were noticed which were considered as polyembryos. Generation of multishoot from attached polyembryos (appeared as single embryo) was also considered as polyembryos. Highly significant variations were observed among the six varieties of wheat for formation of polyembryos over caryopsis, germination of polyembryos over total embryos and formation of polyembryos accounted to multishoots over total embryos. The highest number of polyembryos formation and germination of polyembryos were observed in the variety Mayoor. The varieties Sebia and Mayoor gave the highest polyembryos formation accounted to multishoots which were more than $8.00 \%$.
\end{abstract}

Key words: Wheat (Triticum aestivum L.), haploids, polyembryos

\section{INTRODUCTION}

Haploid plants are utilized in developing doubled haploid (DH) lines for varietal improvement within a short time. Haploids when diplodized to produce DHs, fix the allelic heterozygosity to homozygosity immediately. Therefore homozygous lines could be obtained as early in $\mathrm{F}_{2}$ or $\mathrm{F}_{3}$ generation after crossing. Moreover it improves the selection efficiency of wheat breeding program (Soyma and Khanna, 2002). Wheat haploids are produced through anther and microspore culture and wide crosses of wheat with bearly, maize, pearl millet etc. Among these techniques now a days wheat $\mathrm{x}$ maize cross has got

\footnotetext{
${ }^{1}$ Oilseed Research Centre, ${ }^{2}$ Pulses Research Centre, Regional Agricultural Research Station (RARS), Ishurdi, Pabna, Bangladesh
} 
more importance for production of haploid in wheat. Among wide crosses wheat $\times H$. bulbosum cross was first reported to produce haploids in wheat (Barclay, 1975) but it is less preferable because it is sensitive to wheat crossability due to presence of $\mathrm{Kr}_{1}$ and $\mathrm{Kr}_{2}$ genes of wheat which inhibit such cross (Sitch et al. 1985). Wheat haploid production relies heavily on crosses with $H$. bulbosum and on anther culture procedures influenced by genotypic specificity but wheat $\mathrm{x}$ maize system is usually generalized to cover wide range of genotypes (Riera-Lizarazu and Mujeeb-Kazi, 1993). During the development of embryos in crosses only wheat chromosomes are retained and the chromosomes of the male parents (maize) are eliminated in early stage of zygotic cell division (Laurie and Bennet ,1988). Sometimes polyembryos are found in a single caryopsis in course of haploid production which added an extra advantage to get increased number of haploid plants. Wheat cultivars show different ability to produce polyembryo during wheat $\mathrm{x}$ maize crosses (RosarioLinacero et al., 1996 and Khan et al., 2004). Varietal differences of wheat for regeneration of polyembryo into haploid plants were clearly observed. Therefore, the present research program was undertaken to develop a protocol for the production of haploids and to assess the genotypic variation of wheat varieties for the production of haploids and polyembryos through wheat $\times$ maize system.

\section{MATERIALS AND METHODS}

The experiment was carried out in the green house and tissue culture laboratory of the Department of Genetics and Plant Breeding, Bangladesh Agricultural University, Mymensingh, during the period from October, 2005 to June, 2006. Six varieties of spring wheat namely Mayoor, Sebia, Bulbul, Bijoy, Prodip and Sowgat were used as female parents and one maize variety, Pop corn was used as male parent in wheat $\times$ maize cross. These varieties were sown in the earthen pots in different dates to synchronize flowering of wheat varieties with that of maize. At booting stage both wheat and maize plants were transferred in the green house where the temperature was maintained at $25^{\circ} \mathrm{C} / 18^{0} \mathrm{C}$ day/night with $16 \mathrm{~h} / 8 \mathrm{~h}$ day/ night photoperiod. Pollination was done consecutively two days for better setting of caryopsis. Post pollination treatment was done by application of 2, 4-D at $100 \mathrm{ppm}$ concentration. The hormone 2, 4-D was taken in a hypodermal syringe and an amount of 0.5 $\mathrm{ml}$ was injected into the uppermost internode of the tiller bearing crossed spike on the second day of pollination. On the same day a drop of the hormone was poured on the ovary of each pollinated floret. On the next day one drop of 2, 4-D was again poured on the pollinated florets. After 16-18 days of pollination the spikes with developed caryopsis were harvested. These caryopses were surface sterilized by treating with $70 \%$ ethyl alcohol for five minutes. The treatment with alcohol was followed by treatment with commercial bleach (chlorox containing 4.7\% chlorine) supplemented with a few drops of Tween-20 for 15 minutes. The caryopses were then washed 4 to 5 times with doubled distilled water for five minutes. To extract embryos, the caryopsis were placed under the focal view of stereomicroscope and dissected by using fine pointed forceps. When the embryos were found floating in the fluid of dissected caryopsis, they were picked up and put on the solid MS medium contained in the culture petridish. All of the operations were done in sterile condition under a laminar airflow cabinet. For the germination of embryos, the vials were kept in the dark room at $25^{\circ} \mathrm{C}$ temperature for 3 days. After germination of embryos, when the coleoptiles were about $1-2 \mathrm{~cm}$ long, they were transferred in the culture room at $25^{\circ} \mathrm{C}$ with $16 \mathrm{~h}$ photoperiod provided by using fluorescent lamps. After 15-20 days of germination 
of embryos, the regenerated plants developed roots and shoots and some of them showed multishooted plants from a single embryo .The regenerated plants were transferred in cubicles containing sterile soil with sufficient organic matter. The cubicles were covered by transparent polythene bags and kept in growth chamber for hardening. In the growth chamber temperature was maintained at $16-18^{\circ} \mathrm{C}$ with 4500 Lux light intensity. After 8-9 days of keeping the regenerated plants in growth chamber, bags were removed and plants were transferred in green house. When the plants attained $10-12 \mathrm{~cm}$ in height, they were transferred in larger earthen pot with normal soil in the green house. In the green house, temperature was maintained at $25^{\circ} \mathrm{C} / 18^{0} \mathrm{C}$ days/ night with $16 \mathrm{~h} / 8 \mathrm{~h}$ photoperiod.

Data were taken on a number of florets crossed, caryopsis developed, and number of embryos obtained (number of single embryos and polyembryos), number of embryos germinated (single shoot regenerating embryos and multi shoots regenerating embryos) and number of plants regenerated were recorded in percentage. These data were transformed by arcsine transformation and analyses of variance for different parameters were performed following the principles of randomized complete block design (RCBD). The difference between the treatments means were compared by the least significant difference (Lsd) test. The regenerated plants were confirmed to be haploids by counting their somatic chromosome number (Fig. 4) and also by checking their pollen sterility.

\section{RESULTS AND DISCUSSION}

Analysis of variance for different parameters explaining the efficiency of production of haploids in wheat varieties are given in the Table 1. Significant variations were observed among the varieties for caryopsis developed from the pollinated florets, embryos obtained from caryopsis, single embryo rescued from caryopsis and regeneration of plants over total

pollinated florets. The results suggest that genotypic variation were present among the varieties Mayoor, Sowgat, Prodip, Sebia, Bulbul and Bijoy for production of haploids in spring wheat. The parameters germination of embryos and regeneration of plants over the total embryos exhibited no significant variation among the varieties. Performance of the varieties for the efficiency of haploid production is presented in Table 2. Caryopsis developed over pollinated florets ranged from $29.16 \%$ to $64.72 \%$. The variety Sebia produced $64.72 \%$ caryopsis over pollinated florets, which was significantly higher than the rest of the varieties. Among the varieties Mayoor and Prodip produced more than $50 \%$ caryopsis, and Sowgat and Bijoy produced more than 30\% caryopsis, where as the variety Bulbul produced the lowest number of caryopsis (29.16\%) over pollinated florets. Hejazi et al. (1998) reported $11.11 \%$ to $100 \%$ caryopsis setting in their wheat $\mathrm{x}$ maize crosses. Rosario- Linacero et al. (1996) pollinated different wheat varieties with maize pollen and reported caryopsis development within the range from $53.71 \%$ to $69.05 \%$ over pollinated florets. Verma et al. (1999) found that $34.3 \%$ to $93.70 \%$ caryopsis setting over pollinated florets in their experiment.

Total number of embryos rescued were separated into number of single embryos (Fig.1) and polyembryos (Fig. 2). Number of single embryo formation obtained from the caryopsis showed significant variation among the varieties. The embryos were also different shapes and sizes. The variety Bijoy produced the highest number of embryos, while the variety Bulbul produced the lowest number of embryo from the caryopsis. Verma et al. (1999) reported the recovery of embryos ranging from $8.4 \%$ to $10.2 \%$ from different genotypes of wheat from wheat $x$ maize crosses. Khan et al. (2004) obtained a range of 
$14.70 \%$ to $23.80 \%$ embryos among the spring wheat varieties Gourab, Protiva, Kanchan, Agrani and Ananda. Garcia et al. (2004) reported $2.6 \%$ to $6.0 \%$ embryo formation with wheat $\mathrm{x}$ maize crosses. In the present study the average of the single embryo formation was $19.675 \%$ over the caryopsis with the range of $17.27 \%$ to $23.56 \%$.

Table1. Analysis of variance for haploid production ability among wheat varieties

\begin{tabular}{lccc}
\hline \multicolumn{1}{c}{ Source of variation } & Replication & Variety & Error \\
\hline Degrees of freedom & 2 & 5 & 10 \\
Caryopsis developed from pollinated florets (\%) & 1.311 & $564.974^{* *}$ & 30.469 \\
Embryos obtained from caryopsis (\%) & 12.738 & $29.533^{* *}$ & 4.747 \\
Single embryo rescued from caryopsis (\%) & 13.027 & $22.569^{*}$ & 4.695 \\
Germination of embryos over total embryos (\%) & 8.307 & $104.907^{\mathrm{NS}}$ & 77.641 \\
Regeneration of plants over total embryo (\%) & 40.353 & $134.914^{\mathrm{NS}}$ & 45.220 \\
Regeneration of plants over total pollinated florets (\%) & 0.989 & $15.548^{*}$ & 3.105 \\
\hline
\end{tabular}

$*, * *$ indicate significant at $5 \%$ and $1 \%$ level of probability respectively

$\mathrm{NS}=$ Means nonsignificant

Table 2. Variation among wheat varieties for efficiency of haploid plants developed from wheat $\times$ maize crosses

\begin{tabular}{c|c|c|c|c|c|c|c}
\hline Variety & $\begin{array}{c}\text { Caryopsis } \\
\text { developed } \\
\text { from } \\
\text { pollinated } \\
\text { florets } \\
(\%)\end{array}$ & $\begin{array}{c}\text { Embryo } \\
\text { rescued } \\
\text { from } \\
\text { caryopsis } \\
(\%)\end{array}$ & $\begin{array}{c}\text { Single } \\
\text { embryo } \\
\text { rescued } \\
\text { from } \\
\text { caryopsis }\end{array}$ & $\begin{array}{c}\text { Multiple } \\
\text { embryos } \\
\text { rescued } \\
\text { from } \\
\text { caryopsis } \\
(\%)\end{array}$ & $\begin{array}{c}\text { Embryo } \\
\text { germination } \\
\text { over total } \\
\text { embryo }(\%)\end{array}$ & $\begin{array}{c}\text { Regene- } \\
\text { ration } \\
\text { over } \\
\text { total } \\
\text { embryo } \\
(\%)\end{array}$ & $\begin{array}{c}\text { Regeneration } \\
\text { over total } \\
\text { pollinated } \\
\text { florets }(\%)\end{array}$ \\
\hline Mayoor & $53.51 \mathrm{a}$ & $24.56 \mathrm{a}$ & $19.73 \mathrm{ab}$ & $13.67 \mathrm{a}$ & $49.21 \mathrm{a}$ & $25.84 \mathrm{a}$ & $8.57 \mathrm{a}$ \\
& $(64.51)$ & $(17.52)$ & $(11.72)$ & $(5.70)$ & $(57.30)$ & $(19.38)$ & $(2.35)$ \\
Sowgat & $35.60 \mathrm{~b}$ & $23.97 \mathrm{a}$ & $22.42 \mathrm{ab}$ & $7.938 \mathrm{~b}$ & $46.21 \mathrm{a}$ & $16.72 \mathrm{a}$ & $3.74 \mathrm{ab}$ \\
& $(34.09)$ & $(16.73)$ & $(14.73)$ & $(1.99)$ & $(52.15)$ & $(8.55)$ & $(0.43)$ \\
Prodip & $53.25 \mathrm{a}$ & $17.47 \mathrm{~b}$ & $17.47 \mathrm{ab}$ & $0.500 \mathrm{c}$ & $32.76 \mathrm{a}$ & $12.80 \mathrm{a}$ & $3.12 \mathrm{~b}$ \\
& $(64.1)$ & $(9.06)$ & $(9.06)$ & $(0.00)$ & $(29.44)$ & $(7.03)$ & $(0.40)$ \\
Sebia & $64.72 \mathrm{a}$ & $19.46 \mathrm{ab}$ & $17.60 \mathrm{ab}$ & $7.813 \mathrm{~b}$ & $42.83 \mathrm{a}$ & $27.06 \mathrm{a}$ & $7.71 \mathrm{ab}$ \\
& $(80.70)$ & $(11.21)$ & $(9.35)$ & $(1.84)$ & $(46.25)$ & $(20.88)$ & $(1.83)$ \\
Bulbul & $29.16 \mathrm{~b}$ & $19.57 \mathrm{ab}$ & $17.27 \mathrm{~b}$ & $9.893 \mathrm{ab}$ & $37.88 \mathrm{a}$ & $28.01 \mathrm{a}$ & $4.30 \mathrm{ab}$ \\
& $(23.81)$ & $(11.21)$ & $(8.33)$ & $(2.98)$ & $(38.41)$ & $(22.53)$ & $(0.55)$ \\
Bijoy & $36.39 \mathrm{~b}$ & $24.62 \mathrm{a}$ & $23.56 \mathrm{a}$ & $5.447 \mathrm{bc}$ & $43.43 \mathrm{a}$ & $28.65 \mathrm{a}$ & $6.79 \mathrm{ab}$ \\
Average & $(35.22)$ & $(17.35)$ & $(16.02)$ & $(1.29)$ & $(47.22)$ & $(23.61)$ & $(1.40)$ \\
\hline
\end{tabular}

N.B. The figures in the parenthesis are the variety wise transformed mean values of the original values. The figures having same letter(s) are statistically identical.

Germination of embryo was estimated over total embryos.The range of embryo germination was $32.76 \%$ to $49.21 \%$ (Table 2). The variety Mayoor showed the highest $(49.21 \%)$ germination of embryos, while the variety Prodip showed the lowest number of embryo germination. Khan et al. (2004) reported about $29.06 \%$ embryo germination in the variety Gourav, when crossed with maize. Chen et al. (1999) reported that germination on embryo was around $45.00 \%$ of the total embryos through wheat $\mathrm{x}$ maize crosses. 
Nonsignificant variations were observed among the varieties of wheat for regeneration of haploid plants from the embryos. The range of regeneration of haploid plants was $12.80 \%$ to $28.65 \%$ with an average of $23.18 \%$ over total embryos (Table 2). The highest performance was shown by the variety Bijoy $(28.65 \%)$ followed by Bulbul $(28.01 \%)$. The variety Prodip showed the lowest performance (12.80\%) for regeneration of plants estimated over the embryos. The wheat variety Mayoor, Sebia showed more than $25.00 \%$ and Sowgat showed more than $15.00 \%$ of regeneration of haploid plants over total embryos . Sharmeen et al. (2005) observed $14.54 \%$ to $35.55 \%$ regeneration of haploid plants over total embryos through wheat $\mathrm{x}$ maize crossing system. Varietal differences for regeneration of haploid plants over pollinated florets were significant.
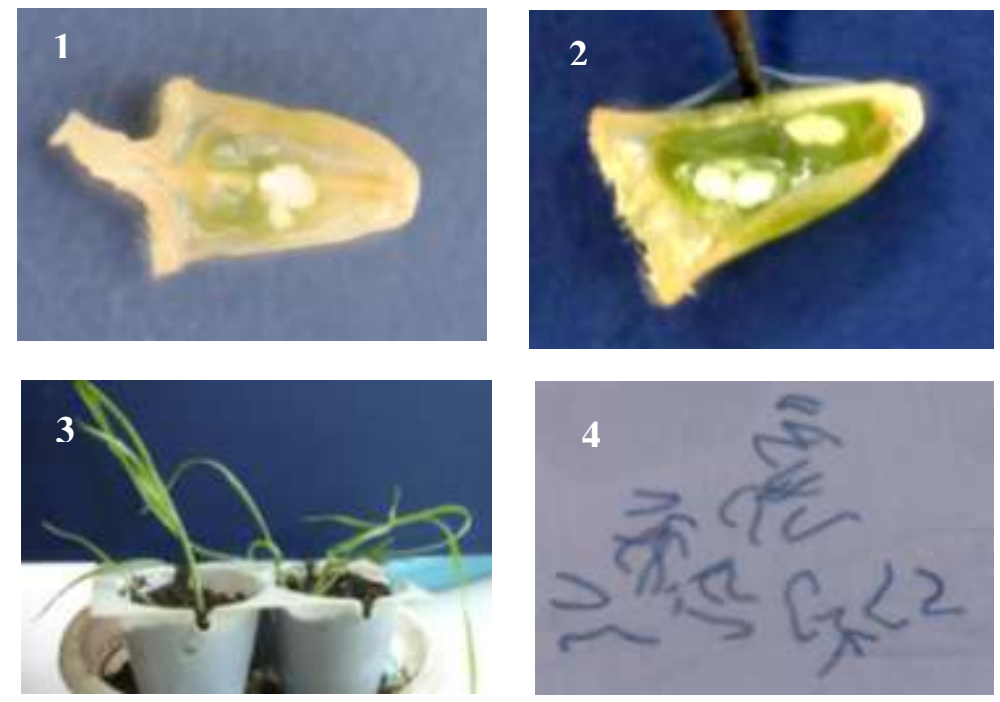

Fig 1-4. (1) Single embryo in haploid caryopsis. (2) Polyembryo in haploid caryopsis. (3) Haploid plants on the cubicles in the green house. (4) Chromosomes of haploid plants

In the present study, regeneration of haploid plants (Fig. 3) over pollinated florets ranged from $3.127 \%$ to $8.577 \%$ with an average of $5.71 \%$.The variety Mayoor regenerated the highest number of plants $(8.57 \%)$ and Prodip showed lowest amount of plant regeneration. The variety Sebia and Bijoy also showed good plant regeneration over the pollinated florets. Verma et al. (1999) obtained 9.90\% haploids seedlings over pollinated florets by crossing wheat with maize. Shamsuddin (2003) reported haploid plant regeneration over pollinated florets ranging from $3.45 \%$ to $7.56 \%$.In the study the overall varietal efficiency in producing haploid embryos and the regeneration of haploid plants suggest that the variety Mayoor produced the highest number of regenerated haploid plants from the embryo over the total embryos and ranked second when regenerated plants were assessed over the pollinated florets. This variety ranked second in rescuing the single embryos from the caryopsis and ranked first for germination of embryos .The variety Sebia took the second position for the regeneration of haploid plants over the embryos and ranked first over the number of pollinated florets. Again this variety stood first in producing single embryo and stood second in germination of embryos. Therefore, the varieties Mayoor and Sebia may be considered as parents for haploid breeding program in wheat. 
During the rescue of embryos from the wheat caryopsis sometimes more than one embroys were found indicating the induction of polyembryony when crossed wheat with maize. Analysis of variance for the production of polyembryos is shown in the Table 3 . Significant variations were observed for the production of polyembryos over caryopsis, germination of polyembryos over total embryos and polyembryo account to multishoot over total embryos. The result suggests that genotypic variation were present among the varieties, Mayoor, Sowgat, Prodip, Sebia, Bulbul and Bijoy for the parameters related to production of polyembryo in spring wheat.

Table 3. Analysis of variance for production of polyembryos in wheat $\times$ maize crosses

\begin{tabular}{lccc}
\hline Source of variation & Replication & Variety & Error \\
\hline Degrees of freedom & 2 & 5 & 10 \\
Polyembryo over caryopsis & 3.210 & $58.250^{* * *}$ & 1.565 \\
Germination of polyembryos over total embryo & 56.383 & $312.886^{* * *}$ & 18.039 \\
Polyembryo accounted to multishoot over total embryo & 5.021 & $140.779^{* * *}$ & 1.237 \\
\hline$* * *$ Means significant at $0.1 \%$ level of probability & \multicolumn{3}{c}{}
\end{tabular}

Table 4. Variation among the varieties for induction of polyembryo through wheat $x$ maize crosses

\begin{tabular}{l|c|c|c}
\hline Variety & $\begin{array}{c}\text { Polyembryo over } \\
\text { caryopsis }(\%)\end{array}$ & $\begin{array}{c}\text { Germination of polyembryo } \\
\text { over total embryo }(\%)\end{array}$ & $\begin{array}{c}\text { Polyembryo accounted to } \\
\text { multishoot over total embryo (\%) }\end{array}$ \\
\hline Mayoor & $13.73 \mathrm{a}(5.7)$ & $31.86 \mathrm{a}(28.422)$ & $16.16 \mathrm{~b}(7.85)$ \\
Sowgat & $7.937 \mathrm{bc}(1.99)$ & $16.72 \mathrm{~b}(11.365)$ & $4.417 \mathrm{~d}(1.515)$ \\
Prodip & $0.500 \mathrm{~d}(0.00)$ & $0.500 \mathrm{c}(0.00)$ & $7.233 \mathrm{c}(4.16)$ \\
Sebia & $7.660 \mathrm{bc}(1.84)$ & $21.65 \mathrm{~b}(13.813)$ & $20.50 \mathrm{a}(12.36)$ \\
Bulbul & $9.893 \mathrm{~b}(2.98)$ & $19.32 \mathrm{~b}(15.87)$ & $7.740 \mathrm{c}(4.76)$ \\
Bijoy & $5.680 \mathrm{c}(1.29)$ & $15.22 \mathrm{~b}(7.87)$ & $3.487 \mathrm{~d}(3.70)$ \\
Average & 7.566 & 17.545 & 9.924 \\
\hline
\end{tabular}

N.B. The values having same letters are statistically identical. The figures in the parenthesis are the variety wise transformed mean values of the original values

Variation among the varieties for induction of polyembryo through wheat $\mathrm{x}$ maize crosses is shown in Table 4. Development of polyembryo over caryopsis ranged from 0.50 $\%$ to $13.73 \%$. The variety Mayoor produced $13.73 \%$ polyembryo over caryopsis which was significantly higher than the rest of the varieties. Khan et al. (2004) obtained $2.70 \%$ to 5.50 $\%$ polyembryo over caryopsis from the varieties Gourav, Protiva, Kanchan, Agrani and Ananda. Performance of the varieties for germination of polyembryo over the total embryos was evaluated. Among the six varieties the highest percent of polyembryo germination over total embryos was found in the variety Mayoor that was $31.86 \%$ (Table 4) The variety Prodip showed the lowest amount of polyembryo germination over the total embryos $(0.50 \%)$.In the present experiment the performance of polyembryo germination was on an average $17.545 \%$ with the range of $0.5 \%$ to $31.86 \%$ over the total embryos. Significant variations were observed for formation of polyembryo accounted to multishoots among the six varieties of wheat.The highest percent of polyembryo formation over total embryos was found in the variety Sebia and that was about $20.50 \%$ (Table-4). The variety Mayoor produced $16.16 \%$ polyembryo formation. Among other varieties Prodip and Bulbul produced more than $7.00 \%$ polyembryo accounted to multishoot. The variety Bijoy showed the lowest number of polyembryo formation over the total embryos (4.41\%). Rosario-Linacero et al. (1996) 
obtained polyembryony from two of the three genotypes of wheat and they were considered from formation of multishoots in seedling. Among their three varieties Thatcher and Chris produced $20.19 \%$ and $7.06 \%$ polyembryony respectively, whereas the varieties Dollar produced no polyembryo.

Production of polyembryo in the wheat varieties through crossing with maize gives an additional benefit to obtain higher number of haploid plants. In the present study, the variety Mayoor performed better for polyembryo over caryopsis and germination of polyembryo (Table 4). This variety also ranked first in the regeneration of haploid plants over the total pollinated florets (Table 2). This result suggests that the variety Mayoor could be used in crossing program for haploid breeding in wheat. In addition the variety Sebia also performed better for production of haploids in wheat. So, the varieties Mayoor and Sebia may be selected as parents for haploid breeding program in wheat. The variety Mayoor appeared as the best among the six varieties of spring wheat for the formation of polyembryony. Higher number of polyembryos in the variety Mayoor resulted increased number regenerated haploid plants in this variety and it is followed by Sebia and Bulbul. Therefore, polyembryos obtained here considered as an added advantage for regeneration of higher haploid plants through wheat $\times$ maize crosses.

\section{REFERENCES}

Barclay,I. R. 1975. High frequencies of haploid production in wheat (Triticum aestivum L.) by chromosome ellimination. Nature (London). 256: 410-411.

Chen, J., Griffey, M. Chappell, J. Shaw, T. Pridgen, D. Natabi and W. Zhao. 1999. Efficiency of haploid production using wheat by maize hybridization method. Virginia Polytechnic Institute and State University, Blacksburg. VA24001.

Garcia- Liamas, C., M. C. Ramirez and J. Ballesteros. 2004a. Effect of pollinator on haploid production in durum wheat crossed with maize and pearl millet. Plant Breed. 123(2): 201-203.

Hejazi, S.M.H.Z., H. Zeinali and A. H. Poor. 1998. Study of different factors in wheat haploid production through crossing with maize. Iranian J. Agric. Sci. 29(1): 207225.

Khan, M. S. H., A. K. M. Shamsuddin, Q. N. Ahmad and H. Rahman. 2004. Haploid production in wheat (Triticum aestivum L.) through wheat $\times$ maize system. Bangladesh J. Pl. Breed. Genet. 17(1): 01-06.

Laurie D. A. and Bennett M. D. 1988. Chromosome behaviour in wheat $\mathrm{x}$ maize, wheat $\mathrm{x}$ sorghum and barley and barley $\times$ maize crosses. In: P.E. Brandham (ED), Kew chromosome Conf. III. 167-177. HMSO, London.

Riera-Lizarazu, O. and A. Mujeeb-Kazi.1993.Polyhaploid production in the Triticeae: wheat × Tripsacum crosses. Crop Sci.33 (5): 973-976.

Rosario-Linacero., G. Marisa., B. Lopez., R. Concepsion., A. David., Laurie and M. V. Ana. 1996. Genotypic differences in polyembryo formation and somatic embryogenesis increment in wheat (Triticum aestivum L.), following 2,4-D treatment. Euphytica. 89: 345-348.

Soyma-Sharma and V. K. Khanna. 2002. Maize mediated polyhaploid wheat production: Scope and procedure. J. Agril. Sci. Soc. North East India.15: 115-118. 
Sitch, L. A., J. W. Snape and S. J. Firman. 1985. Interchromosomal mapping of crossability genes in wheat (Triticum aestivum). Theor. Appl. Genet. 70:309-314.

Shamsuddin A. K. M. 2003. Prodouction of haploids through wheat $\mathrm{x}$ maize cross and their utilization in wheat improvement. An annual report. Dept. of Genetics and Plant Breeding. BAU. Mymensingh.

Sharmeen, F., L. Rahman, M. S. Alam and A.K.M. Shamsuddin. 2005. Variation in the induction of Haploid and Polyemryony in spring wheat through wheat $\mathrm{x}$ maize system. Plant Tissue Cult. 15(1): 7-14.

Verma, V., N. S. Bains, G. S. Mangat., G. S. Nanda. , S. S. Gosal, Kuldeep Singh, V. Verma and K. Singh. 1999. Maize genotypes show striking differences for induction and regeneration of haploid wheat embryos in the wheat $\times$ maize system. Crop-Sci. 39: $1722-1727$. 